\title{
GERAKAN IMPRESIONISME, DEBUSSY DAN “CLAIR DE LUNE”: SEBUAH REFLEKSI TERHADAP PERUBAHAN
}

\author{
Daniel Sema \\ Sekolah Tinggi Theologia Abdiel \\ danny_sema@yahoo.com
}

\begin{abstract}
Impressionism derives its source of inspiration from external, even exotic sources; its literature, art and music are easily projected outside; the recipient of its colorful images has the means of comparing photoreality with the artist's experience of it. This impressionism movement starts from painting, then penetrated into other arts fields. Impressionism has changed the way people view art. It has been considered the setting stone of Modern Art. In general, impressionism has changed the perspective of art, itself.
\end{abstract}

Keywords: impresionisme, seni lukis, musik, komposer, romantikisme

\section{Pendahuluan}

Impresionisme tidak terbatas pada seni musik saja; bahkan, sebelumnya sudah muncul gerakan impresionisme dalam bidang seni rupa yang dimulai sekitar tahun 1870an. Kata impresionisme sebagai sebuah aliran seni (lukis) diambil dari judul sebuah lukisan karya Claude Monet Impression, Soleil Levant yang dalam bahasa Indonesia ialah "Kesan, Matahari Terbit." Istilah itu disandangkan kepada karya Monet dan kawan-kawan oleh kritikus seni Louis Leroy dalam tulisannya di surat kabar Paris, Le Charivari.

Awal gerakan impresionisme bermula sebagai berikut: pada awal tahun 1860, pelukis Claude Monet, Pierre-Auguste Renoir, Alfred Sisley, dan Frédéric Bazille memiliki pandangan yang sama tentang gaya lukisan. Keempat pelukis muda ini lebih tertarik untuk melukis pemandangan dan kehidupan kontemporer lainnya dibandingkan dengan melukis kisah sejarah, tema religi dan potret. Tak lama kemudian pelukis-pelukis lain seperti Camille Pissarro, Paul Cézanne, dan Armand Guillaumin bergabung bersama dengan kelompok mereka.

Académie des Beaux-Arts mempunyai tradisi mengadakan pameran lukisan yang dilombakan. Dalam salah satu pamerannya pada acara lomba lukis tersebut juri selalu menolak karya Monet dan kawan-kawannya, termasuk lukisan the Luncheon on the Grass karya Édouard Manet. Alasan utamanya adalah lukisan itu mengetengahkan objek perempuan setengah telanjang. Mereka dengan sangat pedas mengkritisi Manet karena 
karyanya itu. Akan tetapi Napoleon III malah mengindahkan lukisan-lukisan yang ditolak itu dan mempersilahkan masyarakat umum untuk menilai karya-karya tertolak tersebut. Hasilnya, kontroversi lukisan mereka malah mendatangkan daya tarik tersendiri.

Pada tahun 1867 Monet, Renoir, Pissarro, Sisley, Cézanne, Berthe Morisot, Edgar Degas, dan beberapa seniman lainnya mendirikan Société Anonyme Coopérative des Artistes Peintres, Sculpteurs, Graveurs dan mengadakan pameran mereka sendiri demi untuk memperjuangkan idealisme mereka karena lukisan mereka ditolak untuk dipamerkan di ruang-ruang pameran publik. Ini membuat beberapa pelukis frustrasi dan oleh karena tekanan ekonomi dan kebutuhan untuk eksis di dunia seni lukis semakin kuat, kondisi ini akhirnya membuat Renoir dan Manet meninggalkan idealisme mereka demi untuk bisa diterima oleh Académie des Beaux-Arts. Langkah ini akhirnya memang membuat mereka menjadi seniman sukses. Walaupun demikian, kegigihan Monet dan kawan-kawan dalam memperjuangkan idealisme akhirnya membuahkan hasil dengan diterimanya seni lukis gaya impresionis dalam blantika dunia seni lukis. ${ }^{1}$

Gerakan impresionis kini bahkan memberikan pengaruh kuat terhadap bidang seni lain, khususnya seni sastra dan seni musik. Menjelang tahun 1880-an di Perancis juga muncul suatu gerakan dalam bidang sastra yang bisa disamakan dengan gerakan impresionisme, yaitu simbolisme. Gerakan ini mencoba menuangkan gagasan mereka lewat isyarat daripada pernyataan langsung. Sastrawan seperti Baudelaire, Verlaine, dan Marllamé memilih kata-kata bagi karya-karya puisi mereka bukan karena maknanya, melainkan karena alasan bunyi dan rimanya. ${ }^{2}$

Dalam bidang musik, impresionisme mengacu kepada sebuah gaya komposisi yang terkesan kabur oleh karena hadirnya ambiguitas harmoni yang tercipta oleh tangga nada whole-tone, kromatik dan pentatonis. Memang hakekat dari sifat musik impresionis yang tidak stabil mampu membuat suasana lebih impresionistik daripada seni lainnya. Komposer yang sering dikaitkan dengan impresionisme ialah Claude Debussy (1862-1918) dan Maurice Ravel (1875-1937). Karakteristik yang membedakan musik mereka dengan musik-musik sebelumnya ialah,

1. Penekanan ada pada warna suara dan bunyi instrumen daripada melodi,

2. Karya orkestra sudah tidak menggunakan lagi sebagian besar instrumen perkusi dan instrumen tiup logam—satu-satunya perkecualian ialah instrumen horn dan beberapa instrumen perkusi yang kedengaran lembut seperti fingercymbal,

\footnotetext{
${ }^{1}$ Harry Eiss, The Joker (Cambridge: Cambridge Scholars, 2016), 207 - 209.
}

${ }^{2}$ Connie E. Mayfield, Theory Essenstials (Boston: Schirmer, 2003), 482. 
3. Membangkitkan suasana meditatif dan bernuansa mistis,

4. Tidak lagi menggunakan ritme yang kuat dan tegas untuk mendorong musik,

5. Bercerita tentang sesuatu (musik program), walaupun bukan kisah nyata,

6. Lebih suka menulis komposisi musik tentang air atau laut, misalnya: Jeux d'eau (Mata Air) oleh Ravel, Reflets dans l'eau (Pantulan dalam Air) oleh Debussy, La mer (Laut) oleh Debussy, dan Ondine (Dewi Air yang memikat pria hingga mati) oleh Debussy dan Ravel. $^{3}$

Komposer impresionis lain adalah Dukas and Roussel (Perancis), Frederick Delius dan Cyril Scott (Inggris), de Falla (Spanyol), Respighi (Italia), Charles Loeffler dan Charles Griffes (Amerika Serikat). Kontribusi yang paling besar yang dihadirkan oleh musik impresionis ialah penggunaan harmoni dan tangga nada baru yang memberikan peluang kepada komposer masa depan untuk lebih mengembangkannya. Impresionisme telah menginspirasi sejumlah besar gerakan dalam bidang seni.

Dalam sejarah seni, khususnya musik, impresionisme terletak di penghujung abad XIX dan awal abad XX (era Modern); ini artinya seni impresionis adalah jembatan menuju suatu era baru, suatu era yang menampilkan keanekaragaman dan eksperimentasi yang belum pernah dijumpai pada era-era sebelumnya. Ia bagaikan batu penjuru bagi seni modern. Dalam musik Modern segala sesuatu dipertanyakan, termasuk sistem tonal mayorminor yang sudah digunakan oleh musik Barat selama berabad-abad, panjang komposisi pun berubah total: bisa sangat pendek atau bahkan sangat panjang; segala bunyi boleh dipakai, tidak ada perbedaan antara bunyi musikal dan bunyi keributan (noise). Suatu era yang membingungkan dan kontroversial bagi penikmat musik klasik. Kini muncul pertanyaan bagi kita, mengapa hal ini terjadi dan mengapa impresionisme harus lahir? Tidak adakah akhir dari suatu pergolakan? Mungkinkah impresionisme lahir sebagai akibat faktor di luar seni itu sendiri: faktor sosial, politik, budaya, ekonomi, teknologi bahkan teologi? Jika memang demikian, peristiwa ini bisa menjadi refleksi bagi kita.

\section{Apakah Impresionisme itu?}

Impresionisme adalah nama gerakan seni lukis Perancis yang dipelopori oleh Manet, Renoir, dan lain-lain, istilah yang juga dipakai untuk menamai gaya musik, 
terutama yang merujuk kepada karya-karya Debussy. ${ }^{4}$ Perhatian utama pelukis impresionis ialah pada efek cahaya pada objek daripada kehadiran nyata dari objek itu sendiri. Penggambarannya dilakukan dengan cara mengaduk warna sedemikian rupa, sehingga menghasilkan efek yang diinginkan, yang akan lebih baik jika dinikmati dari jarak yang tidak terlalu dekat. Menurut pendapat pelukis impresionis dalam hidup kesehariannya manusia menangkap kesan dari objek yang dilihatnya. ${ }^{5}$

Berbicara tentang impresionisme pada dasarnya tidak bisa dipisahkan dari romantikisme sebab ia merupakan babak akhir dari romantikisme. Pada hakekatnya, impresionisme masih sangat kental dipengaruhi oleh semangat Romantikisme (akhir abad XVIII - awal abad XIX) yang pada dasarnya menegaskan cara pikir masyarakat dalam budaya Barat terhadap diri mereka sendiri dan dunia. Romantikisme lahir bersamaan dengan terjadinya pergolakan politik, ekonomi dan sosial, termasuk Revolusi Amerika (1776) dan Revolusi Perancis (tahun 1789). Romantikisme merupakan reaksi terhadap perubahan drastis akibat Revolusi Industri akhir abad XVIII dan awal abad XIX dan dalam konteks sejarah, Romantikisme merupakan reaksi artistik dan filosofis yang menentang sikap dan gaya hidup yang mendominasi masyarakat abad XVII dan XVIII yang antara lain lebih mengutamakan logika dan akal, keelokan dan kehalusan (refinement), ketertiban, aturan dan tradisi, stabilitas dan harmoni, serta hierarki sosial.

Jadi, pada dasarnya isu-isu yang diperjuangkan oleh romantikisme terhadap sikap hidup dari masyarakat pada abad sebelumnya sama dengan yang diperjuangkan impresionisme, hanya saja impresionisme lebih tertarik kepada hal-hal yang realistis, dan dalam seni, impresionisme memiliki teknik dan cara berekspresi yang berbeda dengan apa yang biasa dipraktikkan oleh seniman-seniman Romantik. ${ }^{6}$

\section{Lahirnya Seni Impresionis}

Seni impresionis dimulai dari seni lukis. Seniman impresionis pada awalnya terinspirasi oleh teori-teori Eugene Delacroix yang merasa tidak puas terhadap perkembangan seni akademi pada masa itu yang terlalu mengikut konsep seni lukis klasik. Ia berpendapat bahwa lukisan tidak selamanya dibentuk dengan pengolahan garis secara

\footnotetext{
${ }^{4}$ Christine Ammer, The Facts on File Dictionary of Music, fourth edition (New York: Facts on File, 2004), 190. Publishers), 1.

${ }^{5}$ John I. Clancy, Impressionism: Historical Overview and Bibliography (New York: Nove Science

${ }^{6}$ https://rwmiller2015art.wordpress.com/2015/07/13/romantic-era-impressionism-comparecontrast/ (diakses 15 Desember 2017).
} 
berlebihan, seperti yang dikembangkan selama ini. Sebaliknya, bagi mereka pengolahan bidang-bidang warna dengan penuh perhitungan akan menghasilkan bentuk lukisan yang tidak kalah menariknya. Kemudian beberapa pelukis secara radikal melanggar aturanaturan pakar akademik dalam menghasilkan lukisan. Lukisan ini tidak lagi berkonsep pada bentuk yang mementingkan garis secara terperinci, tetapi suasana yang dihasilkan dari sebuah lukisan diwujudkan dengan cara menangkap kesan (impression) cahaya yang ditangkap sekilas oleh mata. Akibatnya, bentuk objek menjadi lebih sederhana, tidak seperti lukisan naturalisme atau realisme.

Pelukis-pelukis ini mengkaji bagaimana warna berubah mengikut gerakan dan suasana, bagaimana cahaya mengubah permukaan dan ruang. Seni foto dan seni cetak potongan kayu ala Jepang sangat mempengaruhi seni impresionis. Karya-karya impresionisme umumnya merekam pemandangan alam dan aktivitas manusia dalam gaya hidup modern, misalnya suasana kota, stasiun kereta api, keramaian jalan raya, pelabuhan serta suasana perkotaan.

Hal yang mirip juga terjadi pada seni musik. Jika pada era Barok tampak teknik kontrapung yang hebat dan ornamentasi yang menawan, era Klasik menampilkan strukturnya yang teratur dan seimbang, seniman era Romantik berekspresi dengan bebas, maka musisi impresionis suka kepada tekstur lembut, suasana berkabut dan penuh aneka warna bunyi. Gaya seperti ini tidak ditemukan pada era Romantik yang cenderung ekspresif; suatu babak baru telah dimulai dalam bermusik.

Di samping faktor internal bagi lahirnya impresionisme, faktor eksternal tampaknya juga berperan sangat penting. Pada tahun 1900 awal Eropa dan Amerika Serikat mengalami suatu keadaan yang sangat makmur, stabil dan damai. Pertumbuhan ekonomi sangat tinggi, standar hidup menjadi jauh lebih baik dan penemuan ilmu pengetahuan banyak menyumbangkan bagi kesehatan dan kenyamanan. Keadaan dan situasi seperti ini berdampak serius terhadap seluruh cabang seni (sastra, lukis, patung, arsitektur, dan musik), yang pada saat berikutnya melahirkan apa yang disebut Modernisme, yaitu suatu gerakan terhadap pembaharuan kesadaran diri.

Seniman, penulis dan cendikiawan bereaksi keras terhadap aturan-aturan yang diberlakukan pada abad XIX dengan membuat eksperimen yang radikal dan gerakan revolusioner. Komposer menolak tonalitas, yang merupakan fondasi harmoni dari musik abad XVII, dan mulai menggunakan bentuk-bentuk harmoni baru secara radikal. Salah satu 
komposer yang melakukan ini adalah Debussy, di samping Schoenberg dan Stravinsky. ${ }^{7}$ Pendeknya, seni impresionis lahir dari kesadaran-diri dan ketidakpuasan akan apa yang dilakukan oleh seni masa lampau.

\section{Lukisan Impresionis sebagai Inovasi Optik}

Para seniman impresionis sangat bervariasi, baik latar belakang kehidupan, kepercayaan, maupun gaya melukisnya, mereka memiliki ciri masing-masing. Walaupun demikian, ada satu hal yang sama yang diperjuangkan yaitu menciptakan cara baru dalam menikmati suatu objek seni dan cara baru dalam melukis yang mencerminkan gaya hidup modern. Seniman impresionis sangat sadar bahwa ide-ide mereka sangat radikal, dan ini akan memberikan pengaruh sangat besar terhadap cara pandang masyarakat terhadap seni. Walaupun dikritik habis-habisan, namun mereka tetap tidak bergeming. Ambisi mereka ialah menciptakan seni dengan gaya unik khas mereka sendiri sekalipun dilecehkan orang. Fokus dan tujuan mereka ialah agar seni impresionis dikenal, dipromosikan dan mampu memengaruhi orang lain untuk bisa melihat seni dengan cara baru.

a. Teori Warna

Dalam penggunaan warna, pelukis impresionis secara dramatis memisahkan diri dari tradisi. Kemajuan pada bidang optik dan teori warna memikat pelukis ini. Dengan bekerja di luar rumah, pelukis impresionis mempermainkan sinar matahari dan warna alam dengan palet warna yang lebih berani dan lebih terang daripada yang digunakan pelukis studio klasik. Pada tahun 1666, Sir Isaac Newton telah menunjukkan bahwa cahaya putih dapat dipecah menjadi banyak warna, termasuk tiga warna primer, merah, biru, dan kuning oleh prisma. Pelukis impresionis belajar menciptakan warna prismatik dengan palet pigmen warna murni yang tajam dan putih. Tidak seperti pelukis sekolahan, yang menutupi kanvas mereka dengan lapisan cat gelap, pelukis impresionis tidak melapisi sama sekali kanvas putih, tidak memberikan latar belakang abu-abu pucat dan tidak menutup dengan warna cream pucat agar efek lukisan yang didapat lebih tipis dan lebih terang.

\section{b. Bahan Seni}

Teknologi baru dalam bahan seni membuat pigmen warna yang lebih beraneka tersedia. Pada masa lalu, seniman harus menggiling dan mencampur pigmen warna mereka sendiri dengan minyak. Kini, pelukis sudah bisa mendapatkan cat dan bahan siap pakai di toko-toko seni. Selain itu, penemuan tube logam yang bisa dilipat kini menggantikan

\footnotetext{
${ }^{7}$ Jeremy Yudkin, Understanding Music (New Jersey: Prentice Hall, 1999), 317.
} 
wadah penyimpanan cat model lama. Lagi pula tube ini mampu mengawetkan pigmen warna lebih lama.

c. Fotografi

Salah satu penemuan dari Revolusi Industri yang paling mempengaruhi impresionisme adalah kamera, belum ada benda lain yang pengaruhnya melebihi kamera. Foto hitam dan putih bukan hanya digunakan untuk merekam suasana untuk dijadikan sebagai bahan ajar, melainkan juga digunakan untuk menangkap momen kehidupan nyata yang diburu para seniman impresionis. Sebagian besar seniman impresionis memiliki kamera: Monet punya empat dan Degas bereksperimen dengan salah satu model awal Kodak portabel. Mereka mencipta komposisi aneh, tak terduga dan asimetris yang kadang tertangkap kamera.

Dengan menolak pengelompokan subjek gambar sebagai pusat lukisan menurut kebiasaan seni tradisional tidak berarti seniman impresionis menempatkan subjek di ujung lukisan dan membiarkan tengah-tengahnya kosong. Degas menyebut foto sebagai "lukisan dari sesuatu yang bergerak dengan sangat cepat dan terjadi secara ajaib" dan ia sangat mahir dalam mencipta komposisi lukisan yang "tidak berpusat". ${ }^{8}$ Selain itu, Degas juga tertarik dengan mesin gambar-bergerak yang baru ditemukan yang dengan panel bukatutup katupnya (rana) yang bergerak dengan kecepatan sangat tinggi mampu menangkap banyak gambar dari binatang yang sedang bergerak. Seniman impresionis sangat getol mempelajari panorama alam dan melihatnya dari perspektif datar. Monet memperhatikan bahwa jika rana bergerak lambat maka sosok yang ditangkap akan terlihat kabur. Gagasan ini mulai dipraktikkannya dalam teknik lukisannya. Bagi mata manusia normal tentu saja tidak ada objek yang tampak kabur; oleh karena itu, Monet dikritik atas lukisan "seorang pejalan kaki” yang kelihatan kabur.

d. Jepangisme

Pengaruh visual lainnya terhadap seni impresionis adalah fenomena yang disebut Jepangisme. Pembukaan diplomasi dan perdagangan oleh Jepang di negara-negara Barat pada tahun 1854 menyebabkan sentimen hebat orang-orang Perancis terhadap segala hal yang berbau Jepang. Produk-produk Jepang disambut antusias oleh kalangan kelas menengah yang sedang bertumbuh di Paris dan dijadikan objek lukisan oleh pelukispelukis impresionis. Mereka terutama menyukai tulisan dan lukisan pada cetakan balokbalok kayu, lalu menirunya, baik warnanya yang cerah, bentuknya yang dekoratif,

\footnotetext{
${ }^{8}$ http://www.impressionism.org/teachimpress/browse/aboutimpress.htm (diakses 12 Desember 
coraknya yang tidak terlalu detail, serta komposisinya yang asimetris ke dalam karya-karya lukisan mereka.

Seni cetak Jepang yang elegan itu (yang dikenal sebagai "ukiyo") juga sangat menginspirasi seni cetak baru. Di samping seni cetak pada balok-kayu, para seniman impresionis juga mencipta lithograf (seni cetak gambar pada batu basah yang bahan dasarnya tinta bercampur minyak) dan etching (seni cetak gambar yang diukir pada pelatpelat logam dengan menggunakan asam). Metode ini mendorong Degas, Monet, Cassatt, dan seniman-seniman lain untuk memperbanyak hasil karya mereka sehingga mampu menjangkau konsumen yang lebih luas.

Pada masa-masa awal, pelukis impresionis kesulitan mendapatkan pasar. Mereka saling berselisih pendapat, menarik diri dari pameran-pameran lukisan; bahkan Monet dan Renoir berpindah gaya lukis untuk menarik calon pembeli. Cézanne juga berpaling dari impresionisme karena ia kecewa, gagal membuat impresionis kokoh dan tahan lama seperti gaya seni lukis lainnya. Namun, seorang penjual barang seni Paris yang visioner, Paul Durand-Ruel, mengakui kehebatan dan memperjuangkan seni lukis impresionisme sejak tahun 1870. Dia secara teratur membeli, menjual, dan mempromosikan lukisan impresionis selama bertahun-tahun dan akhirnya, di tahun 1880-an dan 90-an, dan dunia mulai merangkul seni impresionis. Kolektor seni Amerika banyak membeli lukisan impresionis dan ini memberikan keuntungan yang sangat besar bagi sang pelukis sehingga mereka terus bisa berkarya. Lukisan impresionis yang 25 tahun yang lalu hanya dihargai 50 Franc, kini dihargai sebesar 50.000 Franc. Yang menyebabkan ada perubahan dahsyat itu ialah kemampuan pelukis impresionis dalam meningkatkan daya tarik mereka terhadap kolektor borjuis, sehingga karya mereka dianggap sebagai seni baru untuk kelas baru. ${ }^{9}$

Barangkali yang menjadi daya tarik seni impresionis untuk masa sekarang ialah warna, spontanitas dan kesegarannya. Sebelum pameran pertamanya tahun 1847 , kritikus seni Armand Silvestre memberikan gambaran tentang karya impresionis sebagai:

Sebuah cahaya pirang menyelimuti mereka, dan segala sesuatu tampak sukacita, jernih, bagai festival musim semi, malam keemasan, atau laksana pohon apel yang sedang mekar. Mereka adalah jendela yang terbuka, sehingga tampak di luar hamparan pedesaan yang menyenangkan, sungai-sungai yang penuh dengan kapal-kapal sukacita yang terbentang di kejauhan, di atas tampak langit bercahaya berselimut kabut tipis, di alam terbuka, terhampar luas dan menawan hati. ${ }^{10}$

\footnotetext{
${ }^{9}$ https://kiamaartgallery.wordpress.com/2015/05/07/impressionism-the-influence-of-japonisme/ (diakses 10 desember 2017).

${ }^{10} \mathrm{http}: / /$ www.impressionism.org/teachimpress/default.htm/ImpressionismPaintings Collected by European Museums: A Resource Packet for Educators (diakses 17 Juni 2017).
} 


\section{Debussy dan Impresionisme}

Claude Debussy lahir di Saint-Germain-en-Laye dekat kota Paris pada tanggal 22 Agustus 1862 dan meninggal di Paris pada tanggal 25 Maret 1918. Sejak kecil Claude Debussy diasuh oleh bibinya karena kedua orangtuanya sangat miskin. Debussy kecil belajar piano di bawah bimbingan Mme. Maurède Fleurville, seorang mantan murid dari F. Chopin. Karena kemajuan bermain pianonya sangat pesat hingga pada usia sebelas tahun, Debussy muda diterima masuk di Paris Conservatory.

Di konservatori tersebut para pembimbingnya, terutama Marmontel dan Durand, tidak mengerti apa sebabnya Debussy bersikukuh untuk terus bereksplorasi dengan melodi dan harmoni baru yang bertentangan dengan prinsip-prinsip textbook musik pada waktu itu. Dua guru tersebut butuh beberapa tahun untuk bisa memahami petualangan musiknya di dalam bakatnya yang luar biasa. Debussy juga memenangi beberapa kompetisi bergengsi di Eropa dan sempat melakukan tour-concert ke beberapa negara Eropa, seperti: Perancis, Italia dan Austria pada musim panas tahun 1880, kemudian bekerja di von Meck estate di Rusia tahun 1881 dan 1882. Tahun 1885 Debussy memenangi Prix de Rome, sebuah penghargaan paling bergengsi untuk bidang seni, dengan membawakan cantata L'Enfant Prodigue.

Sekembalinya ke Paris, Debussy berjumpa dengan seniman-seniman yang memberinya inspirasi untuk membuat gerakan baru dalam bidang seni di Paris. Mereka di antaranya adalah penyair simbolis Mallarmè serta pelukis impresionis Manet dan Degas. Setelah menyerap inspirasi dari mereka, Debussy berpikir untuk mencipta suatu jenis musik yang kedengaran lembut, memberikan efek jernih, dengan suasana halus dan terkesan samar-samar (berkabut). Kebetulan Debussy berkenalan dengan musisi eksentrik Zerik Satie.

Satie sangat melawan musikalitas Romantisme Jerman yang bentuk musiknya besar dan menekankan pada emosi yang meledak-ledak. Ia mencari musik yang khas Perancissingkat padat, tidak berlikut-liku, bentuknya kecil dan pengolahannya ekonomis. Tak kurang ambisi Satie ini sangat mempengaruhi Debussy yang makin mantap dengan pilihan jenis musiknya. Dalam waktu tak begitu lama, Debussy menghasilkan banyak karya-karya puncak (masterworks) yang mengorbitkan namanya sebagai seorang musisi impresionalis. Karya-karya itu antara lain: Quartet in G Minor (29 Desember 1893), The Afternoon of Faun (L'Après-midi d'un Faun) yang terinspirasi oleh puisi Mallarmè (22 Desember 
1894), Nocture untuk orkestra, dan yang paling penting ialah opera Pellèas et Mèllisande untuk drama Maurice Maeterlinck.

Meskipun banyak mendapat kritik terhadap musiknya, Debussy terus berkarya menurut caranya sendiri-musik untuk piano, orkes dan vokal. Debussy dikenal sebagai pelopor aliran musik yang dikenal sebagai impresionisme. Ia sangat piawai mengolah warna bunyi, mencipta mood yang halus dan efek jernih dan lembut dalam musiknya. Efek-efek itu diperolehnya dengan mengubah bahasa harmoni dengan cara baru, yaitu tidak menyelesaikan akor-akor disonan dan menggerakkan akor dengan sangat bebas keluar dari tangga nada induknya (tonal center). Ia mencipta melodi yang kedengaran eksotis dengan cara sering menggunakan tangga nada whole-tone yang membuatnya populer, sepopuler tangga-tangga nada lainnya. Dengan cara-cara ini Debussy berhasil membangkitkan indahnya dunia mimpi yang kelihatan samar-samar, yang belum pernah dilakukan orang lain sebelumnya.

Di samping karya operanya yang hebat, Pellèas et Mèllisande, karya-karya puncak Debussy mencakup banyak komposisi untuk orkestra, piano, kombinasi musik kamar, dan vokal. Karya-karya orkestranya yang terbaik ialah $\mathrm{La} \mathrm{Mer,} \mathrm{The} \mathrm{Afternoon} \mathrm{of} \mathrm{Faun,}$ Nocture, dan Images (termasuk "Iberia"). Ia juga mencipta sekumpulan musik untuk piano, termasuk dua buah prelude, dua buah étude, Suite Bargamasque (di dalamnya terdapat "Clair de Lune" yang terkenal), arabesque, Estampes, dua buah Images, dan suita ceria Children's corner. Karya-karya musik vokalnya adalah "Mandoline," "Paysage sentimental," dua seri Fêtes galantes; karya-karya musik kamarnya antara lain Quartet in G Minor dan tiga buah sonata. ${ }^{11}$

\section{Pengolahan Warna Bunyi Musikal}

Tiga orang musisi besar pada era Modern adalah Schoenberg, Stravinsky dan Debussy. Tiga tokoh ini dianggap sebagai pembaharu atau penemu bagi jalan menuju era Modern dalam musik. Jika Schoenberg terkenal dengan "twelve tone series"-nya, Stravinsky dengan eksperimentasi terhadap berbagai macam bentuk pola ritme, maka Debussy dikenal karena pengolahan warna bunyi musikal (tone colour)-nya yang variatif.

Musik Debussy dianggap sebagai serangan terhadap bahasa musik abad XIX. Ia tidak lagi percaya kepada aturan harmoni abad XIX dan dengan torinya sendiri keluar dari rasa tonalitas. Debussy terus meneliti berbagai kemungkinan yang bisa dihasilkan dari

\footnotetext{
${ }^{11}$ David Ewen, The Home Book of Musical Knowledge, (Englewood Cliffs: Prentice-Hall, 1965),
} 44-46. 
instrumen musik orkes. Ia menolak pendapat yang sudah lama dianut bahwa instrumen gesek itu pada prinsipnya dipakai untuk mengungkapkan perasaan atau bersifat liris. Ia juga melihat bahwa kelompok instrumen tiup kayu (woodwind) juga bisa menghasilkan bermacam-macam warna suara, seperti halnya suara manusia; demikian halnya dengan kelompok instrumen tiup logam (brass).

Pendek kata, dalam musiknya Debussy mengolah susunan orkes yang sudah baku (seksi gesek, tiup kayu dan logam) untuk menghasilkan suasana impresionis seperti layaknya seorang pelukis impresionis. Dalam musiknya seolah-olah setiap seksi instrumen berfungsi sebagai solis, sehingga kedengaran bagai sebuah ansambel musik-kamar yang sangat besar. Akhirnya, Debussy mengeksplorasi suara piano dengan mengkombinasikan nada-nada perdelapan, perempat atau setengahan agar menimbulkan suasana khas yang ilutif. ${ }^{12}$ Dalam hal tangga nada, Debussy juga menggunakan tangga nada enam-not yang berjarak sama (whole tone scale) ${ }^{13}$, yang bila not-notnya yang berdekatan dimainkan akan menimbulkan suasana mistis. ${ }^{14}$

\section{Clair de Lune}

Clair de Lune (sinar bulan) adalah judul movement ketiga dari Suite Bergamasque untuk piano yang terdiri atas empat movement. Movement pertama "Prélude" merupakan pembuka dengan banyak menggunakan frase-frase legato yang mengalir; movement kedua, "Menuet"; movement keempat, "passepied", yang memiliki suasana lebih lincah, dengan tempo cepat dan lebih staccato daripada movement pertama. Menurut konteksnya, "Clair de Lune" bersifat kontras dengan movement kedua dan keempat.

Suita ini, yang mula-mula ditulis tahun 1890 tetapi direvisi menjelang publikasinya tahun 1905-karena ada sedikit masalah dengan pihak penerbit-, menunjukkan kepiawaian Debussy dalam musik piano. Bergamasque adalah tarian yang kaku dan agak kasar yang berasal dari penduduk asli Bergamo yang terletak di kaki gunung Alpen, Italia. Penduduk di sana dikenal kaku dan agak kasar, sehingga tarian Bergamasque dihubunghubungkan dengan badut atau lelucon. Sebenarnya, karya ini mula-mula diberi judul "Promenade Sentimentile" oleh Debussy, lalu dalam perkembangannya diganti dengan

\footnotetext{
${ }^{12}$ https://www.britanica.com/print/article/154804, "Claude Debussy: Evolution of His Work." (diakses pada 10 Juli 2017).

${ }^{13}$ Hanya ada dua macam whole tone scale, yaitu: $\mathrm{F}-\mathrm{G}-\mathrm{A}-\mathrm{B}-\mathrm{C} \#-\mathrm{D}$ \# dan F\# - G\# - A\# - C $-\mathrm{D}-\mathrm{E}$.

${ }^{14}$ Leon Gunther, The Physics of Music and Color, (Massachusetts: Department of Physics and Astronomy Tufts UniversityMedford, Springer Science \& Business Media, LLC 2012), 373.
} 
"Clair de Lune" yang diambil dari puisi karya Paul Verlaine tahun 1869 yang merujuk kepada bergamasque. Clair de Lune sering diperdengarkan di bioskop-bioskop, acara dan iklan TV dan sebagai soundtrack film untuk film Giant atau latar belakang film Ocean Eleven. $^{15}$

Memang, sebuah judul karya seni boleh jadi menjadi titik tolak penting bagi sebuah penafsiran. Sebuah lukisan tertentu akan mempunyai arti yang sangat berbeda kalau diberi judul yang lain (atau sama sekali tidak ada judulnya); demikian pula dengan judul musik. Judul menunjukkan kepada pengamat apa yang perlu diperhatikan, apa yang menjadi pusat pengamatan. Debussy tentu punya alasan agar karya musiknya ini diinterpretasikan sebagai "cahaya bulan" dengan kata lain, pendengar digiring untuk mampu menginterpretasikan karyanya sesuai dengan maksudnya. Dan jika benar seperti yang dikatakan oleh filsuf Danto bahwa sebuah interpretasi merupakan pertalian erat antara karya dan substrat (zat kimiawi) materiilnya ${ }^{16}$ maka bunyi-bunyi musikal dalam komposisi Debussy akan terkait erat dengan judul yang diusungnya, dan ini akan membuahkan interpretasi cahaya bulan di malam yang cerah, tenang, samar, berkabut dan temaram.

Saya sendiri terpikat oleh karya ini karena atmosfir yang dihadirkan, suasana berkabut, samar, halus, jernih, dan temaram sangat terasa melalui pengolahan kombinasi nada, progresi dan struktur harmoninya yang unik. Jika dimainkan dalam format orkestra, aneka warna bunyi instrumen dengan berbagai tingkat register memperluas dimensi ketemaraman, kekaburan, serta kemistisan yang ingin dicapai. Bagi saya, penggambaran cahaya bulan di malam yang teduh ini sangat tepat.

Clair de Lune boleh dikatakan representasi sempurna dari sebuah karya musik impresionis. Karya ini memenuhi apa yang diidealkan oleh seniman impresionis: bentuknya singkat padat, tidak berlikut-liku, pengolahannya ekonomis, suasana yang mistis, samar dan temaram yang belum pernah dijumpai pada karya-karya pada masa-masa sebelumnya.

\section{Kepustakaan}

Ammer, Christine. The Facts on File Dictionary of Music, fourth edition. New York: Facts on File, 2004.

\footnotetext{
${ }^{15}$ www.songfacts.com/detail.php?id=30476 (diakses 5 Juli 2017).

${ }^{16}$ Michael Hauskeller, Seni: apa itu?: posisi estetika dari Platon sampai Danto (Yogyakarta: Kanisius, 2015), 101.
} 
Clancy, John I. Impressionism: Historical Overview and Bibliography. New York: Nove Science Publishers.

Eiss, Harry. The Joker. Cambridge: Cambridge Scholars, 2016.

Ewen, David. The Home Book of Musical Knowledge. Englewood Cliffs: Prentice-Hall, 1965.

Gunther, Leon. The Physics of Music and Color. Massachusetts: Department of Physics and Astronomy Tufts UniversityMedford, Springer Science \& Business Media, LLC, 2012.

Hauskeller, Michael. Seni: apa itu?: posisi estetika dari Platon sampai Danto. Yogyakarta: Kanisius, 2015.

Mayfield, Connie E. Theory Essenstials. Boston: Schirmer, 2003.

Yudkin, Jeremy. Understanding Music. New Jersey: Prentice Hall, 1999. 